\title{
A prática de gestão do esporte na perspectiva do lazer em uma instituição cultural
}

\author{
Yuri Bitencourt Martins ${ }^{1}$ \\ Flavia da Cunha Bastos ${ }^{2}$ \\ Lilian Aparecida Ferreira ${ }^{1}$
}

\section{RESUMO}

Objetivo: Analisar a gestão de um programa de esporte no âmbito do lazer e identificar o(s) perfil(is) de gestor(es) manifestados pelos profissionais de uma instituição cultural de ensino. Métodos: $O$ trabalho se orientou pela pesquisa qualitativa, tendo como base um estudo de caráter descritivo e interpretativo, envolvendo: análise documental, entrevista e observação. Participaram do estudo quatro profissionais da instituição referida. Resultados: Após leitura dos dados identificamos um alinhamento entre a diretriz institucional e as perspectivas dos gestores em defesa de uma valorização do esporte enquanto oportunidade de aprendizagem e construção de novos comportamentos e hábitos no que corresponde à prática esportiva. Conclusão: Foi manifestada a dificuldade, por parte dos profissionais, de conjugar as várias ações de gestão dos distintos programas institucionais. Com relação ao(s) perfil(is) de gestor(es) no âmbito do esporte e lazer houve convergência entre os profissionais, atuantes em diferentes instâncias na instituição, ao defenderem uma perspectiva ampliada que valorizava a autoavaliação, saber ouvir e se valer de conhecimentos teóricos relativos à gestão.

Palavras-chave: Gestão do Esporte. Lazer. Expectativas Sociais.

\footnotetext{
1 Universidade Estadual Paulista, Faculdade de Ciências, Bauru - SP, Brasil.

2 Universidade de São Paulo, Escola de Educação Física e Esporte, São Paulo - SP, Brasil.
}

\section{Correspondência:}

Yuri Bitencourt Martins. Universidade Estadual Paulista, Av. Eng. Luís Edmundo Carrijo Coube, 2085, Nucleo Res. Pres. Geisel, Bauru, SP, Email: yuribtmartins@gmail.com 


\section{The practice of sport management in the perspective of leisure in a cultural institution}

\section{ABSTRACT}

Objective: To analyze and manage the sport in the leisure scope and to identify the profile (s) of manager (s) manifested by the professionals of a cultural teaching institution. Methods: The work is oriented to qualitative research, based on a descriptive and interpretative study, involving documentary analysis, interview and observation. He participated in a project of professional initiative of the same age. Results: After reading the data, an alignment was identified between the institutional guideline and the managers' perspective in defense of a woman as an opportunity for learning and a new way of acting. Conclusion: It was manifested a difficulty, on the part of the professionals, to combine things to manage the differences of institutional programs. In relation to the profile (s) of manager (s) in the scope of sports and leisure, there was convergence among professionals, acting in different instances in the implantation, when defending an extended perspective that valued a self-assessment, knowing how to listen and using theoretical knowledge.

Keywords: Sports Management. Leisure. Social Expectations.

\section{La práctica de gestión del deporte en la perspectiva del ocio en una institución cultural}

\section{RESUMEN}

Objetivos: Los objetivos del presente estudio fueron analizar y gestionar el deporte en el ámbito del ocio e identificar el perfil (s) de gestor (es) manifestado por los profesionales de una institución cultural de enseñanza. Métodos: El trabajo está orientado a la investigación cualitativa, teniendo como base un estudio de carácter descriptivo e interpretativo, involucrando: análisis documental, entrevista y observación. Participó en un proyecto de iniciativa profesional de la misma edad. Resultados: Después de la lectura de los datos, se identificó una alineación entre la directiva institucional y la perspectiva de los gestores en defensa de una mujer como una oportunidad de aprendizaje y una nueva forma de actuar. Conclusión: Se manifestó una dificultad, por parte de los profesionales, de conjugar las cosas para gestionar las diferencias de programas institucionales. Con respecto al perfil (s) de gestor (es) en el ámbito del deporte y el ocio hubo convergencia entre los profesionales, actuantes en diferentes instancias en la implantación, al defender una perspectiva ampliada que valoraba una autoevaluación, saber oír y valerse conocimientos teóricos.

Palabras Clave: Gestión Deportiva. Ocio. Expectativas Sociales. 


\section{INTRODUÇÃO}

A abordagem da prática do esporte de lazer e em relação ao direito da população de ter acesso a ela passa a ser garantido pela Constituição Federal do Brasil (BRASIL, 1988, p.20), que no artigo 60, define que: "São direitos sociais a educação, a saúde, a alimentação, o trabalho, a moradia, o lazer, a segurança, a previdência social, a proteção à maternidade e à infância, a assistência aos desamparados, na forma desta Constituição". Em outro artigo da Constituição (Art. 217), o Esporte é tratado em termos das suas práticas, § $3^{\circ}$.: "É dever do Estado fomentar práticas desportivas formais e não-formais, como direito de cada um" (BRASIL, 1988, p. 8).

Apesar da legislação, a situação do esporte no Brasil em âmbito governamental enfrenta diversos obstáculos para concretização e consolidação de políticas públicas ou políticas institucionais no âmbito do esporte na perspectiva do lazer. Segundo Starepravo (2011), pesquisadores da área de políticas públicas de esporte e lazer apontam que existe uma série de barreiras que impedem o desenvolvimento de políticas efetivas envolvendo o esporte e o lazer no Brasil. Veronez (2005) denuncia que o assistencialismo e o utilitarismo concedidos ao esporte e ao lazer são barreiras ao se fazer políticas públicas nessa área. Linhales (2001) sinaliza que a hierarquização de prioridades sociais deixa o esporte e o lazer como últimas demandas a serem atendidas. Para Marcellino (2001) e Amaral (2004), a carência e falta de acesso aos equipamentos esportivos e de lazer são barreiras para que a sociedade possa usufruir de políticas de boa qualidade nestes âmbitos. De acordo com Mezzadri et al. (2007), a construção de políticas tendo como referência apenas a ótica do empirismo, valorização do número de eventos e de pessoas atendidas acabam comprometendo o desenvolvimento de ações efetivas para este campo.

Com base nas indicações acima apontadas por diferentes pesquisadores da área, fica evidente que existem inúmeros desafios a serem superados na consolidação de políticas públicas de esporte e de lazer no nosso país.

Junto aos elementos já indicados, a questão da gestão também se revela como um tema emergente, na medida em que envolve a atenção com a formação de profissionais capacitados e preparados para as diferentes ações que constituem o trabalho de um gestor do esporte na perspectiva do lazer. Tal ação profissional compreende deste 0 entendimento de organizações públicas ou privadas; infraestruturas e materiais institucionais; parcerias entre o setor público e privado; tipo de público atendido e suas expectativas; planejamentos e ações da gestão, ou seja, um perfil profissional que consiga avaliar, organizar e atuar em diferentes setores, buscando a melhor relação entre eles. 
Caminhando nesta direção, Marcellino (2001) defende que políticas públicas para este setor devem ser avaliadas em sua qualidade de acordo com três aspectos: a concepção de lazer dos gestores, que é a visão do lazer como um espaço de aprendizado e bem estar por meio de atividades realizadas; a formação dos agentes, correspondente ao conhecimento que o gestor possui em torno do lazer e do esporte e das relações pessoais, ou seja, a ação em conjunto dos diversos agentes da gestão em prol de resoluções dos problemas que permeiam esse campo.

Segundo Stigger (2009), o esporte parece assumir, para muitos gestores e educadores, no âmbito das políticas públicas, uma perspectiva monocultural ou ainda prescritiva, deixando de considerar que tal fenômeno é mutável e com significações diversas. Neste sentido, as instituições públicas e privadas assumem papel significativo e com possibilidade de transformação, envolvendo propostas atraentes e diversificadas de ensino (BRACHT, 2005), como também, processos de gestão que se proponham a garantir ações consistentes para uma intervenção de boa qualidade na sociedade.

Pesquisar a gestão do esporte no campo do lazer é um desafio, já que se trata de um tema complexo. Neste sentido, esta pesquisa teve como objetivos analisar a gestão de um programa de esporte no âmbito do lazer e identificar o(s) perfil(is) de gestor(es) manifestados pelos profissionais de uma instituição cultural de ensino.

\section{MÉTODO}

Esta pesquisa se assentou na abordagem qualitativa proposta por Bogdan e Biklen (1994), na expectativa de compreender o fenômeno estudado, bem como, in loco estabelecer contato com os gestores de uma instituição cultural de ensino. Dentro das especificidades da abordagem qualitativa, esta investigação se caracterizou por um estudo descritivo e interpretativo que, segundo Hannabuss (1996), tem como objetivo conhecer e relatar o que é vivido por um grupo, buscando conhecer o significado das subjetividades encontradas naquela realidade e auxiliar o pesquisador na interpretação desse ambiente.

O estudo foi composto pelas seguintes fases: contato com a instituição envolvida na pesquisa para solicitação e autorização da realização da pesquisa; aproximação do pesquisador aos sujeitos/colaboradores do estudo; visita in loco do ambiente a ser observado; entrevistas com os participantes do estudo; observação das aulas oferecidas pelo projeto; pesquisa documental com base no material disponibilizado pela instituição. 
A pesquisa foi realizada em uma instituição cultural de ensino, localizada em uma cidade do interior do estado de São Paulo. Essa instituição, de acordo com a pesquisa documental realizada, tem como propósito desenvolver: "[...] uma ação de educação informal e permanente com intuito de valorizar as pessoas ao estimular a autonomia pessoal, a interação e o contato com expressões e modos diversos de pensar, agir e sentir" (Documento Institucional ${ }^{3}$, p.1).

Foram entrevistados sujeitos responsáveis pelo desenvolvimento do programa de esporte na perspectiva do lazer junto à instituição e um dos responsáveis pela criação do mesmo. A opção pela técnica de entrevista semiestruturada visou levantar as perspectivas dos sujeitos vinculados à instituição. Para tanto foi elaborado um roteiro contendo questões relativas aos diferentes aspectos da gestão de um programa de esporte e lazer na instituição. As entrevistas foram realizadas com os ocupantes dos seguintes cargos: instrutor de esportes; monitor de esportes; gerente da unidade; gerente estadual.

Os nomes das pessoas responsáveis e seus respectivos cargos foram mantidos em sigilo para preservar a identidade dos participantes do estudo. Sendo assim, estes foram denominados por PS1, PS2, PS3, e PS4. Tais entrevistas foram registradas em áudio e transcritas na íntegra para posterior análise.

Outra ferramenta utilizada foi a observação do local e de aulas que eram oferecidas pelo programa. Segundo Ricardson (1999), a observação, sob algum aspecto, é imprescindível em qualquer processo de pesquisa científica, pois ela tanto pode conjugar-se a outras técnicas de coleta de dados como pode ser empregada de forma independente e/ou exclusiva. Godoy (1995) aponta que a observação tem um papel essencial, pois quando observamos estamos procurando apreender aparências, eventos e/ ou comportamentos. Foram realizadas 15 observações com o objetivo captar os aspectos referentes à gestão do ensino de esportes nas aulas que eram oferecidas pela instituição, correspondentes aos seguintes grupos: criança (3 a 10 anos), jovem (11 a 15), adulto (16 a 59), idoso (acima de 60 anos).

As informações documentais sobre a instituição foram adquiridas em seu site institucional e no documento específico referente ao Programa Esporte.

Foram respeitados os procedimentos éticos da pesquisa com seres humanos e todos os participantes autorizaram a realização do estudo. Ressaltamos aqui que a seguinte pesquisa foi aprovada pelo Comitê de Ética com seres humanos pela universidade envolvida, sob o número 15459/46/01/11.

A análise dos resultados se baseou na construção de classificações, as quais buscaram a utilização de categorias para ilustrar o fenômeno estudado, como

\footnotetext{
${ }^{3}$ Não foram revelados os dados específicos do documento para garantir o sigilo da instituição pesquisada.
} 
mostra Gomes (1994, p. 70), "[...] as categorias são empregadas para se estabelecer classificações. Nesse sentido, trabalhar com elas significa agrupar elementos, ideias ou expressões em torno de um conceito capaz de abranger tudo isso". No presente estudo as categorias foram definidas a posteriori, pois emergiram do material analisado.

\section{Resultados E Discussão}

Após leitura dos dados e a articulação dos mesmos com a literatura, foi possível identificar as seguintes categorias de análise: 1. Programa de gestão de esporte e lazer; 2. Perfil(is) do(s) gestor(es) de programa voltado ao esporte e lazer.

\section{Programa de gestão de esporte e lazer}

Nesta categoria foram abordadas às concepções e gerenciamento de um programa de esporte na perspectiva do lazer, partindo-se da análise das entrevistas, da pesquisa documental e das observações realizadas com os profissionais envolvidos na instituição.

Em termos conceituais, a gestão do esporte é considerada como o processo de trabalhar com pessoas e recursos materiais para realizar objetivos de organizações esportivas, de maneira eficaz (BATEMAN; SNELL, 1996). Já o lazer, como "[...] cultura vivenciada no tempo disponível" segundo, (MARCELLINO, 1996, p.28).

A partir de princípios e normas da instituição, o programa investigado foi construído com a seguinte missão: "Promover o bem-estar social, a melhoria da qualidade de vida e o desenvolvimento cultural" (Documento Institucional, p.2). Tal programa preocupa-se em deixar bem estabelecido os princípios de cada fase de acordo com a faixa etária, sendo iniciado para pessoas com a idade de 3 a 6 anos, passando pela faixa etária de 11 a 15 anos, os adultos na faixa etária de 16 a 59 anos, e, por fim, o público acima dos 60 anos. Em cada uma das diferentes faixas etárias existem princípios particulares a serem vivenciados pelos alunos e pelos gestores envolvidos. Com relação aos propósitos do programa, os entrevistados sinalizaram que:

O programa funciona para promover atividade física e promover esporte para pessoa desde quando ela inicia sua vida esportiva e até o final, quando ela tá velhinha lá no final da sua vida (PS1).

O programa tem como propósito, desempenhar o máximo de desenvolvimento físico para as crianças, fazendo com que elas desenvolvam suas capacidades de acordo com suas faixas etárias (PS2). 
O objetivo do programa é trabalhar na perspectiva da iniciação da formação esportiva, no desenvolvimento da cultura esportiva, sobretudo pensando na formação de pessoas ao longo da vida (PS4).

Foi possível verificar que as respostas se mostraram coerentes com o que é proposto no documento institucional:

Processo de educação permanente, que objetiva a ampliação do repertório motor dos participantes, incentiva a prática autônoma da atividade físico-esportiva e conscientiza sobre a importância da inclusão de exercícios físicos na agenda diária. (DOCUMENTO INSTITUCIONAI).

O programa, se estabelecendo de modo gratuito, atinge crianças, adolescentes, adultos e idosos oriundos de diferentes classes sociais e econômicas, demonstrando ser um programa que realiza inclusão por meio de atividades de esporte e lazer. Segundo Melo (2008 p. 9), "[...] incluir deve significar preparar o indivíduo para o exercício pleno da cidadania e isso certamente significa desenvolver olhares críticos sobre a realidade que os cerca, não adaptação incondicional a esse modelo de sociedade".

Os propósitos que a instituição pretende com o esporte na perspectiva do lazer, declarados nos documentos analisados, foram:

Esporte para Todos; Atividade Física e Esporte enquanto manifestações culturais; Inclusão pelo e para o Esporte no seu conceito mais amplo: Qualidade de Vida; Difusão da Prática Esportiva. (Documento Institucional)

Esse panorama explicita a proposta da área esportiva e do lazer no programa ao oferecer atividades com objetivo de não focar o ensino do esporte para a competição, procurando com o esporte alcançar outro viés, como o bem estar do indivíduo em praticar uma atividade física. Esses objetivos foram revelados na fala dos entrevistados a respeito do programa:

A gente não trabalha com escolinha de esporte, a gente não trabalha, por exemplo com a mesma classificação das federações ou confederação de determinada modalidade. (PS4)

Por dar essa possibilidade de, por exemplo, pessoas que são adultas, que talvez não teriam outro lugar para praticar uma modalidade que elas gostem, estar participando ou fazendo alguma coisa no seu dia a dia, ou crianças terem a possibilidade de vivenciar diferentes modalidades esportivas, diferentes práticas esportivas, os adolescentes saírem das ruas, terem uma atividade organizada e estruturada, pensando no desenvolvimento deles, psicológico, físico. (PS1) 
O conteúdo das falas vai ao encontro do defendido por Stigger (2009), que considera o esporte a partir de novos caminhos para se propor programas esportivos nos quais as subjetividades dos sujeitos que deles participam tenham visibilidade e espaço.

Quando questionados sobre as exigências que Ihes eram solicitadas com relação ao programa, os entrevistados evidenciaram as diretrizes que a instituição preconizava para o atendimento da sociedade:

Olha os resultados que são cobrados é uma questão de frequência dos alunos para ver se esses estão frequentando normalmente. (PS2)

Nossa preocupação mesmo é com as modalidades esportivas e com a permanência das modalidades que a gente trabalha no ano inteiro e que a gente possa permanecer com as atividades. (PS3)

A gente não tem um desempenho financeiro, porque todas as atividades são gratuitas, mas a gente brinca que o nosso ganha pão é o atendimento, então a gente não ganha dinheiro com o programa, mas precisa ter as nossas turmas cheias, por que tem um investimento muito grande de equipamento, dos espaços, das formações dos professores, a instituição investe muito nisso. (PS4)

Quanto aos aspectos da gestão, especificamente no que correspondia aos recursos humanos e liderança, nas observações realizadas na instituição foi possível identificar a relação entre os profissionais que atuavam no programa. Apesar da hierarquia existente dentro da instituição, envolvendo diferentes tipos de atuação profissional, foi possível notar que a relação entre eles se dava por meio do diálogo constante, de modo a articular a execução e o planejamento das aulas, como também, às questões administrativas do programa.

Em termos de programação e avaliação, foi verificado que ocorriam reuniões semanais entre estes profissionais para discutirem temas relacionados ao programa:

Na verdade aqui, a gente tem uma hierarquia, eu sou quem trabalha diretamente com o público, o meu colega, que fica logo acima do meu cargo, é o responsável pela gestão do que faço e dos estagiários. Acima dele ainda têm o coordenador e a gerência. (PS1)

Então é um contato muito próximo, tanto com os monitores quanto com a gerência. São extremamente abertos e solícitos. Quando a gente pensa em alguma atividade diferente ou estrutura, alguma coisa que foge um pouco dos padrões, enfim [...] (PS1)

As aulas são organizadas diretamente pelos instrutores, então normalmente todo ano a gente tem uma reunião na administração da instituição, onde são passadas ou reafirmadas as diretrizes que serão trabalhadas. Normalmente vou eu, um ou mais relacionado 
ao programa e depois a gente senta e discuti para ver quais serão as estratégias para serem tomadas. (PS2)

Os fragmentos parecem evidenciar que existe uma relação entre diferentes setores para a construção e execução da gestão de esporte e lazer. De acordo com termos ligados à área da gestão, isso é chamado de intersetorialidade, uma lógica de gestão que perpassa diferentes âmbitos das políticas sociais e pressupõe uma articulação entre vários setores das diferentes políticas (BELLINI, 2013). De maneira geral, isso se expressa pela relação na qual diversos cargos que estão dentro da gestão de esporte e lazer devem ouvir, escutar, analisar, planejar e executar da melhor forma coletivamente, atendendo os pressupostos que são previstos pelo programa.

Um propósito recorrente do programa foi o caráter social a ele atribuído. Como sinaliza Zaluar (1994), em virtude do contexto sociopolítico e econômico brasileiro, os projetos sociais e programas alternativos partiram de uma medida emergencial, buscando a complementação ou substituição dos processos educativos formais. Culturalmente, o esporte é bastante vinculado a projetos sociais, sendo considerado um fator decisivo para que as pessoas encontrem sucesso na vida (SILVA, 2007). Rubio (2000, p. 127) amplia este sentido, dando destaque para o caráter simbólico que o contexto esportivo envolve,

O esporte hoje é considerado um dos maiores fenômenos sociais da modernidade. Reconhecido como uma forma elementar de socialização, até uma variedade profissional, o esporte compõe o imaginário social, sendo identificado por elementos, como força, superação de limites, vitória e supremacia quanto valores próprios, refletindo assim o modelo social vigente.

Elementos relacionados à associação do esporte com seu papel social também foram destacados pelos entrevistados: "os adolescentes saírem das ruas, terem uma atividade organizada e estruturada pensando no desenvolvimento deles, psicológico, físico." (PS1)

Tal associação ganhou relevo ao ser apontando que há uma valorização do esporte em si, todavia, esta construção social tende a passar também pelo esporte de rendimento, já que a partir da mídia ocorre toda divulgação de sucesso e fama que grandes atletas conquistam a partir do esporte.

Foi possível perceber, na fala dos entrevistados, algumas dificuldades a respeito do programa com relação à instituição:

Na verdade para mim a grande dificuldade, é o planejamento em si, o planejamento é bastante elaborado, demanda bastante tempo, por conta da correria do dia a dia, às vezes a gente acaba se desprendendo do planejamento. Algumas vezes a gente não consegue seguir exatamente o que a gente tinha pensado por falta de tempo, por mais que a gente consiga planejar, existem outros 
programas que acontecem na unidade, que a gente participa também $[\ldots]$ (PS1)

Existem algumas dificuldades, por que os monitores não ficam "full time" nesse programa, então outras demandas que acontecem na unidade acabam a ter uma certa interferência, porque a gente não consegue dar essa atenção completa ao programa. (PS2)

Tais dificuldades foram identificadas tanto na fala dos entrevistados quanto nas observações, já que a atribuição de funções em outros programas acabava por prejudicar o andamento do gerenciamento das atividades do programa específico de esporte, fazendo com que o planejamento sofresse alterações por substituições de profissionais, sendo um problema no processo das etapas do programa.

Um dos fatores que podem nos ajudar a compreender estas dificuldades se vincula ao fato do programa ainda estar em construção. Embora o mesmo já tenha um tempo considerável de existência, vem sendo implementado de modo inicial em outras unidades do estado, bem como, seu material de referência tem passado por alterações.

[...] existem unidades que estão inserindo o programa, não foi completado ainda um ciclo do programa. Pra você ter uma ideia, a fase dedicada às crianças de 6 a 10 anos, seria ideal que elas ficassem quatro anos no programa, então eu poderia fazer uma avaliação depois de um ciclo de quatro anos completos. Porém ainda não existe esse ciclo de quatro anos completos do programa. (PS4)

Então ele saiu de um estado de projeto para uma realidade e aí a gente ainda busca algumas informações, pra gente entender melhor como vai funcionar esse programa. (PS2)

Esse momento inclusive é um momento interessante do programa, porque nós estamos passando justamente pelo momento da escrita, da documentação do programa em todas as unidades e temos discutidos quais seriam os indicadores para avaliar se esse programa é eficiente ou não. (PS4)

O que podemos perceber, a partir dos depoimentos dos entrevistados, é que - programa ainda carece de uma avaliação ampla e sistematizada que possa alimentar a instituição com os desdobramentos do que vem sendo desenvolvido. Isso parece ter se mostrado como um compromisso institucional e uma demanda importante para a qualificação da gestão realizada. Apesar disso, foi possível observar um esforço efetivo em torno do programa de modo a consolidá-lo, como ilustrou a fala de um dos entrevistados:

Hoje o projeto é reconhecido fora da instituição, ele já foi apresentado em congressos internacionais, os acadêmicos de diversas universidades conhecem o programa, porque são pessoas que a gente aproximou que a gente fez debates e que a gente trouxe inclusive para trabalhar na formação dos nossos professores, então 
é um programa reconhecido e a hora que ele estiver escrito efetivamente e documentado, vai ser mais ainda. (PS4)

\section{Perfil de um gestor de programas voltados ao esporte e lazer}

Essa categoria visa elucidar, na perspectiva das pessoas envolvidas na instituição e no programa investigado, as competências que um gestor deve possuir para desempenhar, da melhor forma, programas voltados ao esporte e ao lazer.

De acordo com os entrevistados foi possível constatar que:

Acredito que uma boa gestão ela gira em cima de um bom planejamento, então um planejamento prévio vai possibilitar que poucos ou menor número de problemas aconteça. (PS1)

Uma boa gestão [...] o ideal seria, ter uma certa exclusividade para gente, buscar novos adeptos e novas crianças, adolescentes, adultos, idosos e explicar essa metodologia, passar nas escolas e ser de repente um complemento de educação escolar, essa é uma educação não formal. Para gente contribuir na formação do indivíduo. (PS2)

Acho que uma das competências maiores é saber ouvir e compartilhar e, com isso, propor cada vez mais o planejamento, acho. (PS3)

Acho que a primeira competência de um bom gestor é a escuta e a observação, ele precisa ouvir a equipe, ele precisa estar junto, então pensando na instituição especificamente, aí não só a equipe na unidade, mas também em relação às questões institucionais, às demandas institucionais e às orientações institucionais. (PS4)

Ao estabelecermos relação entre os fragmentos apresentados e a literatura sobre a temática, podemos depreender que a palavra gestão se relaciona com "planejamento". Neste sentido, os depoimentos se mostram em parte alinhados ao que Karnas (2010, p. 6) define como gestão: "[...] planejamento, organização, direção e controle de organizações esportivas".

Uma observação feita por um dos entrevistados sinalizou que a gestão do programa seria facilitada e a qualidade do serviço melhorada se houvesse exclusividade, ou seja, se a pessoa responsável estivesse exclusivamente vinculada a ele e não atuasse em outros programas.

A gente não consegue canalizar as energias apenas para o programa. Isso eu acho que seria o ideal, se nós conseguíssemos interagir, ou integrar todas as forças unicamente em um programa e tentar desenvolvê-lo da melhor forma. (PS2) 
Todavia, no depoimento de outro profissional vinculado ao programa, houve uma manifestação em favor de um perfil de multitarefas por parte dos gestores, sendo aquele incumbido para realizar várias tarefas ao mesmo tempo.

Honestamente é a gestão do tempo, na verdade é você conseguir otimizar a partir das ferramentas que você tem, você conseguir otimizar as tarefas, normalmente o gestor é aquele cara multitarefa. (PS4)

A divergência de percepção pode sinalizar que aos diferentes papeis de gestores (professores, coordenadores, supervisores, responsável geral) careçam de demandas distintas de atuação profissional, mobilizando formas variadas de perceber estas funções. Esta identificação propõe esforços da comunidade acadêmica para melhor conhecer sobre os aspectos que cercam a gestão, na expectativa de mobilizar novas políticas institucionais no campo do esporte para o lazer.

Quando os entrevistados foram questionados sobre o que seria necessário para que um gestor pudesse atuar em projetos e programas voltados para 0 esporte na perspectiva do lazer, eles assim se manifestaram:

Como gestor você não pode ficar só apontando, e só acusando seus pares, acho que primeiro a gente precisa se olhar, a partir disso querer se tornar uma pessoa melhor, sempre tentar ser melhor. (PS3)

Primeiro estudar muito e estudar não só o que a gente chama hoje em técnicas de gestão ou de projetos de gestão, mas o objeto da gestão também. É fundamental você conhecer o objeto que você vai gerenciar ou que você vai trabalhar. (PS4)

Em segundo exercitar a escuta para você ser um bom gestor. Para mim, isso é fundamental: exercitar a escuta. Não é fácil, isso é muito difícil, porque você, às vezes, enquanto gestor, inclusive, tem que abrir mão de coisas que você acha que deveriam ser feitas para poder ouvir a sua equipe. (PS4)

Como pudemos perceber os entrevistados enfatizam características mais genéricas dos gestores que aquelas que poderiam ser associadas exclusivamente ao campo do esporte e do lazer. Observamos que o gestor deve ser uma pessoa que precisa se autoavaliar, saber ouvir e se valer de conhecimentos teóricos da gestão, de modo a realizar uma atuação profissional de melhor qualidade. Talvez isso também possa revelar uma fragilidade do campo da gestão de esportes na perspectiva do lazer em termos de produções acadêmicas e cursos específicos na área.

Entre os entrevistados foi possível identificar seus perfis de formação e o tempo que atuavam na instituição, conforme segue: "Bacharelado em Educação 
Física, por uma instituição privada, me formei em 2010 e atuo na instituição desde 2014." (PS1)

Tenho formação acadêmica em Física, Matemática e Educação Física. Me formei em uma universidade particular no curso de Educação Física e atuo na instituição no cargo atual desde 2011. (PS2)

Estou na instituição há 23 anos, sou formado em administração de empresas, pós-graduado em administração hoteleira e em gerência de projeto. Estou aqui há, aproximadamente, três anos. (PS3)

Bacharel em Educação Física por uma universidade pública, trabalho na instituição desde 1998. Tenho pós-graduação em lazer e MBA em gestão de projetos. (PS4)

Em relação ao perfil desse gestor esportivo, nossas constatações se alinharam as de Karnas (2010), uma formação dos gestores esportivos circunscrita pela graduação em Educação Física, outra graduação e pós-graduação.

Pela fala dos entrevistados, e reconhecendo a formação destes, é importante ver o quanto uma formação ampliada é valorizada pela instituição. Entretanto, de acordo com Karnas (2010), o conhecimento do esporte, suas regras, aplicações, formas de se relacionar, são particularidades do profissional de Educação Física, diferindo-se de outras formações profissionais.

De acordo com Rocha e Bastos (2011), em diversos países europeus e nos Estados Unidos, há uma crescente tendência para o oferecimento cada vez maior de cursos de formação profissional específica já em nível de graduação, normalmente voltados às ciências do esporte, como licenciatura específica para a área de gestão do esporte.

No caso brasileiro, com o que a literatura vem apontando para a formação do gestor esportivo, a formação do gestor esportivo e de lazer ainda se dá em nível de pós graduação, não havendo uma formação em nível de graduação específica neste campo. Apesar disso, é reconhecido o avanço na área da gestão esportiva e do lazer, seja no âmbito acadêmico, como também nos espaços profissionais demarcados por novos campos de trabalho.

Questionados sobre as dificuldades que eventualmente enfrentariam para exercer as funções de gestores na instituição, os entrevistados responderam:

Lidar com os desafios, conversando trocando ideia. Como a conversa é muito tranquila entre os vários cargos dos profissionais na instituição, então a gente consegue superar esses desafios por meio de conversa. (PS1)

A instituição procura, na medida do possível, nos fornecer tempo para que busquemos algumas informações de modo a integrá-las ao 
programa, então isso a gente vê que é um potencial que a instituição tem. (PS2)

Articulando as fala dos entrevistados com as observações realizadas, foi possível notar que a conversa entre as pessoas envolvidas no programa e na instituição é recorrente e que tais encaminhamentos se dão na base do diálogo entre os membros dos variados cargos, buscando resolver os desafios que encontram. Além disso, notamos um compromisso da instituição com a melhoria da formação de seus profissionais, reconhecendo se tratar de um processo contínuo de desenvolvimento.

\section{CONSIDERAÇÕES FINAIS}

Finalizamos este artigo com os elementos, em forma de síntese, que nos ajudaram a responder as inquietações anunciadas nos objetivos desta pesquisa, a saber, analisar a gestão de um programa de esporte no âmbito do lazer e identificar o(s) perfil(is) de gestor(es) manifestados pelos profissionais de uma instituição cultural de ensino.

Com relação à análise da gestão do programa de esporte no âmbito do lazer desenvolvido pela instituição, levantamos características que dão visibilidade a uma articulação entre as ações dos profissionais e as expectativas documentais definidas institucionalmente. Questões como o envolvimento das diversas fases do desenvolvimento humano (infância até a terceira idade), o foco voltado pela valorização da participação e inclusão dos envolvidos no programa, bem como, a expectativa de oferecer uma vivência que possa mobilizar a autonomia e a melhoria da qualidade de vida dos participantes por meio do esporte se mostraram alinhadas. Notamos com isso uma valorização do esporte enquanto oportunidade de aprendizagem e construção de novos comportamentos e hábitos no que corresponde à prática esportiva, fugindo de um modelo recorrente, ainda hoje presente, que anuncia uma proposta de ensino do esporte ancorado no lazer e o desenvolve sob os moldes do esporte de alto rendimento (ZALUAR, 1994).

Ainda que o alinhamento do que propõe a instituição com o que pensam e desenvolvem os profissionais seja um aspecto muito positivo e que pode auxiliar no encaminhamento de uma boa gestão, foi manifestada a dificuldade, por parte dos profissionais, de conjugar as várias ações em distintos programas institucionais. As demandas de um programa relativamente novo e que envolve diversas faixas etárias pode requer maior atenção dos profissionais e talvez uma dedicação exclusiva poderia contribuir para consolidar o programa e dar mais segurança de atuação no campo da gestão do mesmo.

Correspondente à identificação do(s) perfil(s) do(s) gestor(es) assinalados pelos entrevistados, houve certa convergência entre os profissionais atuantes em 
diferentes instâncias na instituição, demonstrando uma perspectiva ampliada que valorizava a autoavaliação, saber ouvir e se valer de conhecimentos teóricos relativos à gestão.

Os participantes do estudo, a partir de seus perfis de formação e atuação profissionais, demonstraram vínculos estreitos com a Educação Física, seja por ser a primeira ou uma de suas graduações. Além disso, foi constatada uma preocupação institucional com a formação continuada de seus profissionais no campo da gestão, o que parece ter contribuído com a realização de cursos de pósgraduação na área, bem como, espaços e tempos para outros processos formativos.

Reconhecendo que toda investigação é passível de críticas para mobilizar novos esforços dos pesquisadores em busca de tornar seus estudos o mais próximo possível da realidade, uma limitação desta nossa pesquisa esteve em não ter tido condições de observar um volume ainda maior de aulas, bem como, de entrevistar os participantes das aulas. Isso poderia, no cruzamento dos dados, nos trazer novos elementos para análise e, eventualmente, reconfigurar os apontamentos que aqui fizemos.

Em termos dos indícios trazidos por este estudo e que nos alimentam com novas questões, ainda carentes de investigações na área, pontuamos: Em quais aspectos as atuações de gestores da Educação Física se diferem quando nos referimos ao esporte de lazer e ao esporte de alto rendimento? Como isso tem se constituído na área? Quais seriam as diferenças nos papéis de gestores do esporte no âmbito do lazer que atuam em distintos cargos em uma mesma instituição? É possível que tais diferenças sejam desenvolvidas em cursos de formação continuada?

Estas são algumas das várias possibilidades investigativas que a temática da gestão no âmbito do esporte nos incitam a pensar. Esperamos que os leitores possam ampliá-las e, quiçá, se sentirem desafiados a pesquisá-las!

\section{REFERÊNCIAS}

AMARAL, Silvia Cristina Franco. Políticas Públicas. In: GOMES, Christianne Luce. (Org.) Dicionário Crítico do Lazer. Belo Horizonte: Autêntica Editora, 2004. p.181-85.

BELLINI, Maria Isabel Barros; FALER, Camilia Susana; SCHERER, Patricia Terezinha; JESUS, Tiana Brum de; RAMALHO, Livia. Políticas públicas e intersetorialidade em debate. SEMINÁRIO INTERNACIONAL SOBRE POLITICAS PÚBLICAS, INTERSETORIALIDADE E FAMÍLIA, 1., 2014, Porto Alegre. Anais... Porto Alegre: EDIPUCRS,2014. p. 1-11. Disponível em: http://repositorio.pucrs.br/dspace/handle/10923/8133. 
BRACHT, Valter. Sociologia crítica do esporte: uma introdução. Injuí: Ed. Unijuí: 2005.

BOGDAN, Roberto; BIKLEN, Sari Knopp. Investigação qualitativa em educação. Tradução Maria João Alvarez, Sara Bahia dos Santos e Telmo Mourinho Baptista. Porto: Porto Editora, 1994.

BRASIL. Lei no 8.672, de 6 de Julho de 1993. Institui normas gerais sobre desportos e dá outras providências. Diário Oficial da República Federativa do Brasil. Brasília, n .127, p. 9379, 6 de jul. 1993, Seção 1, pt. 1.

GODOY, Arilda Schmidt. Pesquisa qualitativa: tipos fundamentais. Revista de Administração de empresas, v. 35, n. 3, p. 20-29, 1995. Disponível em: http://www.scielo.br/scielo.php?script=sci arttext\&pid=S0034-75901995000300004.

GOMES, Romeu. Pesquisa social: teoria, método e criatividade. 1994. In: MINAYO, Maria Cecília de Souza. A análise de dados em pesquisa qualitativa. Rio de Janeiro: Vozes, 1994. p. 69-80.

HANNABUSS, Stuart. Research interviews. New Library Word. v.97, n. 1129, p. 22-30, 1996. Disponível em:

https://www.emeraldinsight.com/doi/full/10.1108/03074809610122881

KARNAS, Gabriel Silveira. Perfil do gestor esportivo nos países de língua portuguesa: uma revisão de literatura. 2010, 36f. Trabalho de Conclusão de Curso (graduação) Universidade Federal do Rio Grande do Sul, Porto Alegre, 2010.

LINHALES, Meily Assbú. Jogos da política, jogos do esporte: subsídios à reflexão sobre políticas públicas para o setor esportivo. In: MARCELINO, Nelson Carvalho. (Org.) Lazer e esporte: políticas públicas. Campinas: Autores Associados, 2001. p. 31-56.

MARCELLINO, Nelson Carvalho. O entendimento do lazer. In: MARCELLINO, Nelson. Carvalho. (Org.). Políticas setoriais de lazer. Campinas: Autores Associados, 1996, p.1-6.

MARCELLINO, Nelson Carvalho. Lazer e esporte: políticas públicas. Campinas: Autores Associados, 2001.

MELO, Victor Andrade. Projetos sociais: de esporte e lazer: reflexões, inquietações, sugestões. Revista Quaderns d'Animació i educació social, Rio de Janeiro, n. 7, p. 1-24, 2008. Disponível em:

http://www.quadernsanimacio.net/ANTERIORES/siete/VICTOR\%20ANDRADE.pdf.

MEZZADRI, Fernando Marinho; CAVICHIOLLI, Fernando Renato; SOUZA, Doralice Lange de. (Orgs.) Esporte e Lazer: subsídios para o desenvolvimento e gestão de políticas públicas. Jundiaí: Fontoura, 2007. 142p.

RICARDSON, Roberto. Jarry. Pesquisa social: métodos e técnicas. São Paulo: Atlas, 1999.

ROCHA, Cláudio Miranda da; BASTOS, Flávia da Cunha. Gestão do esporte: definindo a área. Revista Brasileira de Educação Física e Esporte, São Paulo, v. 25, n. esp, p. 91-103. 2011. Disponível em: http://www.scielo.br/scielo.php?pid=S1807$\underline{5092011000500010 \& \text { script }=\text { sci abstract\&tIng }=\text { es. }}$.

RUBIO, Katia. Psicologia do Esporte: Interfaces, pesquisa e intervenção. São Paulo: Casa do Psicólogo, 2000. 
SILVA, Fábio Silvestre da. Projetos sociais em discussão na psicologia do esporte. Rev. Bras. Psicol. Esporte, São Paulo, v. 1, n. 1, p. 1-12, 2007. Disponível em:

http://pepsic.bvsalud.org/scielo.php?script=sci arttext\&pid=S1981$\underline{91452007000100005 .}$

STAREPRAVO, Fernando Augusto. Políticas públicas de esporte e lazer no Brasil: aproximações, interseç̧ões, rupturas e distanciamentos entre os subcampos político/burocrático e científico/acadêmico. 2011, 422 f. Tese (Doutorado em Educação Física), Universidade Federal do Paraná, Curitiba, 2011.

STIGGER, Marco Paulo. Lazer, cultura e educação: possíveis articulações. Revista Brasileira de Ciências do Esporte, v. 30, n. 2, p. 73-88, 2009. Disponível em: http://revista.cbce.org.br/index.php/RBCE/article/view/437.

STIGGER, Marco Paulo. Relações entre o esporte de rendimento e o esporte da escola. In: STIGGER, Marco Paulo; LOVISOLO, Hugo (Orgs.). Esporte de rendimento e esporte na escola. Campinas: Autores Associados, 2009, p.103-34.

VERONEZ, Luiz Fernando Camargo. Quando o Estado joga a favor do privado: as políticas de esporte após a Constituição Federal de 1988. 2005. 386 f. Tese (Doutorado em Educação Física) - Faculdade de Educação Física, Universidade Estadual de Campinas, Campinas, 2005.

ZALUAR, Alba. Cidadãos não vão ao paraíso. Campinas: Editora Escuta, 1994. 